TAPROBANICA, ISSN 1800-427X. October, 2011. Vol. 03, No. 02: pp. 110-111.

(C) Taprobanica Private Limited, Jl. Kuricang 18 Gd.9 No.47, Ciputat 15412, Tangerang, Indonesia.

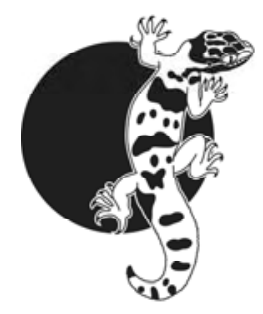

\section{Unusual affiliative behaviour in orang-utans (Pongo pygmaeus) - Sabah, Malaysia}

Adult male and female orang-utans are usually described as solitary (Delgado Jr \& Van Schaik, 2000; Galdikas, 1985; Poole, 1987; Rodman \& Mitani, 1987; Weiss et al., 2006), the female providing the only infant care, as far as is known. Adult males, which are twice the size of adult females, do not associate with females except for sex; adult males may associate with subadult males, but not for companionship: it usually involves competition for a receptive female (Delgado Jr \& Van Schaik, 2000; Galdikas, 1985; Mitani et al., 1991; Schürmann \& van Hooff, 1986). At least, this is the conventional wisdom. While on a wildlifewatching trip to Sabah, Borneo, May 21 to June 5, 2011, the orang-utan groups that Jeffrey Harding and I saw in the wilds of Borneo followed this pattern: mature males alone or unaccompanied females with young. But once, in a semi-wild setting (a large, protected primary forest with a population of orang-utans accommodated to humans), we were watching a female with an infant as they foraged in the trees (Fig. 1). After half an hour of quiet observation, we noticed a mature male approaching. We had seen him earlier about 100 meters away, approaching from a different direction. Although mature and larger than the female, the male was not an old one with flat cheek pads. The female, who was nursing and therefore could not have been in estrus, stopped foraging and watched the male approach with seeming casual interest.

The male came on slowly, swinging from branch to branch and climbing with all four hands down the trunks to reach her elevation, which was just above the ground. Meanwhile, she moved down to a boardwalk for tourists that led to a feeding station. She turned her back to the approaching male, brought her infant up to her face and kissed and hugged it. As she cuddled the infant, the male came around in front of her, put both arms around her and the infant, and hugged them both for several minutes. She then reached out and touched the male's arm, still holding the infant between them with her other arm, and turned her face up to his. They kissed each other square on the lips: a long, lingering, seemingly romantic kiss. Then they separated a few centimetres and she looked straight at the male with a smile, still holding the infant between them, while the male looked down. I am trying not to be anthropomorphic about this, but the male looked bashful-there is no other way to describe it. Then the male turned and swung off into the forest.

It is possible that these orang-utans' behaviour was modified by provisioning: staff fed them fruit at a regular time each morning to attract them for tourists (these observations were not made at feeding time). However, provisioning of chimpanzees at Gombe National Park and Mahale National Park in Tanzania caused intense frustration leading to competition for food, aggression, and, ultimately, murder (Power, 1991). We saw no evidence of aggression at feeding time, when a dozen or so orang-utans were aggregated around the feeding platform. If provisioning had any effect here, it was evidently the opposite, since these two adults were friendlier than the commonly reported orang-utan behavioural repertoire; and the male was careful of the infant. Was this male an old friend of the female? A former or prospective, future mate? A brother? A son? It is impossible to say, but no one can observe an intimate incident like this and take at face value that male orang-utans are solitary with no regard for infants and no interest in females except sex.

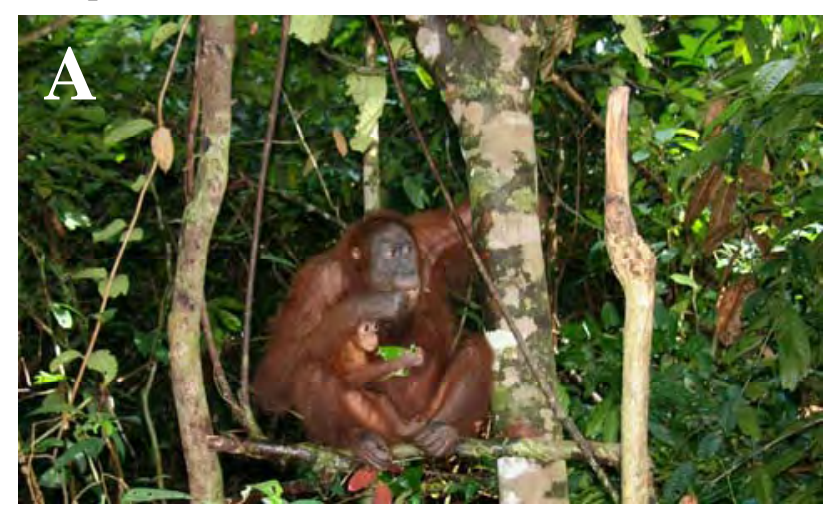



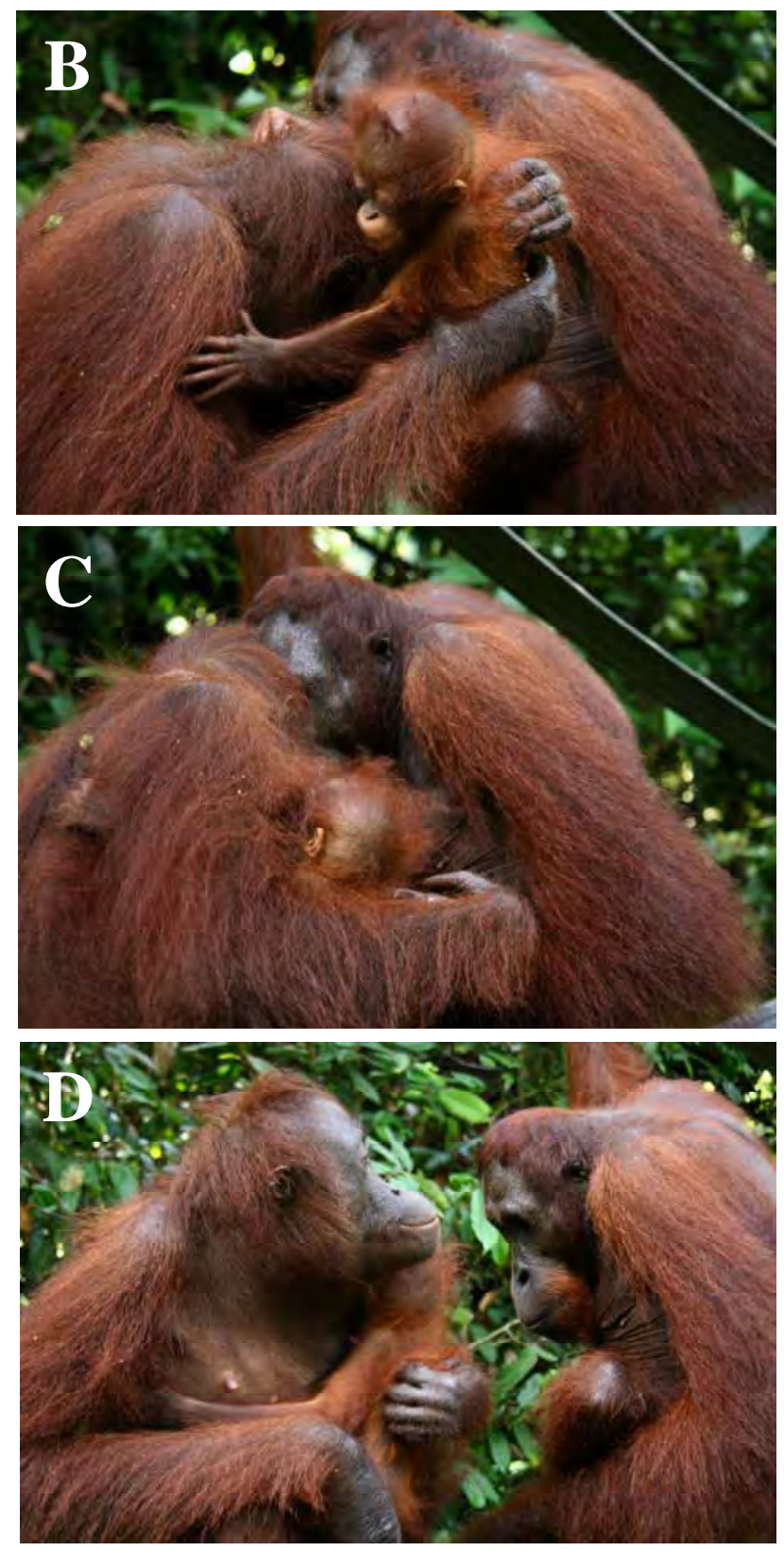

Fig. 1: A partial photo sequence showing the adult female orang-utan noticing the approaching adult male, being hugged by him, kissing him, and then smiling at him; A: the female with infant, feeding on leaves, noticed the male, B: the female hugs the infant while the male hugs them both, C: they kiss, D: she smiles, he looks down

\section{Literature Cited}

Delgado Jr, R. A. and C. P. Van Schaik, 2000. The behavioral ecology and conservation of the orang-utan (Pongo pygmaeus): a tale of two islands. Evolutionary Anthropology: Issues, News, and Reviews, 9: 201-218.

Galdikas, B. M. F., 1985. Orang-utan sociality at Tanjung puting. American Journal of Primatology, 9: 101-119.
Mitani, J. C., G. F. Grether, P. S. Rodman and D. Priatna, 1991. Association among wild orang-utans: sociality, passive aggregations or chance?, Animal Behaviour, 42: 33-46.

Poole, T. B., 1987. Social behavior of a group of orang-utans (Pongo pygmaeus) on an artificial island in Singapore Zoological Gardens. Zoo Biology, 6: 315-330.

Power, M., 1991, The egalitarians-human and chimpanzee. Cambridge, Cambridge University Press: 290.

Rodman, P. S. and J. C. Mitani, 1987. Orang-utans: Sexual dimorphism in a solitary species. In: Primate Societies (Smuts, B. B., D. L. Cheney, R. M. Seyfarth, R. W. Wrangham and T. T. Struhsaker (Eds.). University of Chicago Press, Chicago: 63-101.

Schürmann, C. L. and J. A. van Hooff, 1986. Reproductive strategies of the orang-utan: new data and a reconsideration of existing sociosexual models. International Journal of Primatology, 7: 265-287.

Weiss, A., J. E. King and L. Perkins, 2006. Personality and subjective well-being in orang-utans (Pongo pygmaeus and Pongo abelii). Journal of Personality and Social Psychology, 90: 501.

Submitted: 29 July 2011, Accepted: 29 October 2011

Lee E. Harding SciWrite Environmental Sciences Ltd., 2339 Sumpter Drive, Coquitlam, British Columbia, Canada E-mail: harding@sciwrite.ca 